\title{
Kajian Dampak Lingkungan bagi Rekonstruksi Gedung Sekolah (Studi Kasus: SDN Mekarsari 6, Depok)
}

\author{
Study of Environmental Impact on School Building Reconstruction \\ (Case Study: SDN Mekarsari 6, Depok)
}

\author{
Alimuddin $^{1, a)}$, Rulhendri ${ }^{1, a)}$, Nurul Chayati ${ }^{1, a)}$, Ilmi Dian Rachmawati ${ }^{1, b)}$ \\ ${ }^{1)}$ Program Studi Teknik Sipil, Fakultas Teknik dan Sains, Universitas Ibn Khaldun, Bogor. \\ Koresponden : ${ }^{a}$ alimuddin@ uika-bogor.ac.id \& ${ }^{b}$ Ilmidianrachmawati@gmail.com
}

\begin{abstract}
ABSTRAK
Sebagai salah satu bentuk pelayanan kepada masyarakat, Dinas Perumahan dan Permukiman, Kota Depok berencana merekonstruksi Gedung Sekolah Dasar Negeri Mekarsari 6. Akibat dari kegiatan tersebut memberikan dampak negatif berupa penurunan kualitas udara, peningkatan kebisingan, peningkatan limpasan air permukaan, gangguan kesehatan bagi warga sekitar, dan timbunan sampah domestik yang dihasilkan dari kegiatan konstruksi. Untuk menanggulangi dampak negatif yang terjadi dan mengembangkan dampak positif upaya pengelolaan perlu dilakukan kajian dampak lingkungan yang terjadi pada tahap pra konstruksi, konstruksi sampai tahap operasi. Adapun tujuan penelitian ini untuk mendapat hasil analisis kajian dampak lingkungan dan sosial ekonomi sekaligus cara penanggulangan dalam meminimalisasi dampak yang terjadi pada tahap pra konstruksi, konstruksi sampai tahap operasi. Metode yang digunakan dalam penelitian adalah metode observasi dan metode skoping untuk mengetahui dampak dan penanganan yang baik terhadap lingkungan. Penelitian ini menggunakan data primer berupa survei lapangan, wawancara, dan didukung oleh data sekunder. Hasil penelitian ini adalah diketahui kondisi rona awal lingkungan di lokasi penelitian dan diperolehnya suatu analisa dampak lingkungan yang terjadi dan cara untuk meminimalisir dampak dengan penanganan yang baik agar terciptanya suatu konstruksi yang ramah lingkungan.
\end{abstract}

Kata Kunci : Dampak lingkungan, rekonstruksi gedung sekolah, rona awal lingkungan.

\section{PENDAHULUAN}

Perubahan dan kerusakan lingkungan yang terjadi dewasa ini lebih dikarenakan oleh ulah perilaku manusia. Pembangunan merupakan suatu proses perubahan untuk meningkatkan taraf hidup manusia tidak terlepas dari aktivitas pemanfaatan sumberdaya alam. Dalam aktivitas ini sering dilakukan perubahan-perubahan pada ekosistem dan sumber daya alam. Perubahanperubahan yang dilakukan tentunya akan memberikan pengaruh pada lingkungan hidup. Memperhatikan berbagai dampak pembangunan terhadap lingkungan, pemerintah telah menetapkan kebijakan pengelolaan sumber daya alam dan lingkungan hidup secara tepat untuk mendorong perilaku masyarakat untuk menerapkan prinsip-prinsip pembangunan berkelanjutan (Rellua, 2013). 
Dalam kegiatan rekonstruksi akan menimbulkan dampak terhadap lingkungan baik yang bersifat negatif maupun posistif, maka sesuai dengan ketentuan dan peraturan yang berlaku khususnya di bidang lingkungan hidup berdasarkan Undang-Undang Nomor 32 tahun 2009 tentang Perlindungan dan Pengelolaan Lingkungan Hidup, maka untuk mendukung rekonstruksi yang berwawasan lingkungan perlu dilakukan kajian mengenai dampak lingkungan terhadap wilayah sekitarnya (UU 32/09).

Tujuan dari penelitian ini adalah untuk mengetahui kondisi rona awal lokasi penelitian dan menganalisis dampak lingkungan hidup dan memperoleh cara penanggulangan dari hasil analisis dalam upaya meminimalisasi dampak yang terjadi yang kemudian akan dijadikan acuan agar dapat menjaga lingkungan dengan baik.

\section{TINJAUAN LITERATUR}

\section{Pengertian Lingkungan Hidup}

Menurut Salim (1976), lingkungan hidup diartikan sebagai benda, kondisi, keadaan dan pengaruh yang terdapat dalam ruang yang kita tempati dan mempengaruhi hal yang hidup termasuk kehidupan manusia. Definisi lingkungan hidup ini dapat dikatakan cukup luas. Apabila disederhanakan, ruang lingkungan hidup dibatasi oleh faktor-faktor yang dapat dijangkau manusia, misalnya faktor alam, politik, ekonomi dan sosial.

Soedjono (1979) mengartikan lingkungan hidup sebagai lingkungan fisik atau jasmani yang terdapat di alam. Pengertian ini menjelaskan bahwa manusia, hewan dan tumbuhtumbuhan dilihat dan dianggap sebagai perwujudan fisik jasmani. Lingkungan hidup mencakup lingkungan hidup manusia, hewan dan tumbuh-tumbuhan yang ada di dalamnya

Soemarwoto (1983) berpendapat bahwa lingkungan hidup merupakan semua benda dan kondisi yang ada dalam ruang kita tempati dan mempengaruhi kehidupan kita. Menurut batasan tersebut secara teoritis ruang yang dimaksud tidak terbatas jumlahnya. Adapun secara praktis ruang yang dimaksud selalu dibatasi menurut kebutuhan yang dapat ditentukan.

Menurut Ervianto (2013) dalam Alimuddin (2020) menyebutkan bahwa konstruksi hijau adalah bagian dari konstruksi berkelanjutan dengan tujuan utama mengurangi dampak negatif terhadap lingkungan selama proses pembangunan. Hal ini dimaksudkan agar tujuan pembangunan untuk meningkatkan pendapatan dan kesejahteraan masyarakat dapat tercapai.

Infrastruktur sangat penting untuk kehidupan daerah: kehidupan ekonomi, sosial dan administrasi. Infrastruktur sengaja dibangun untuk memenuhi fungsi tertentu yang mutlak dibutuhkan. Oleh karena itu, infrastruktur harus dikelola dengan baik agar infrastruktur tersebut selalu berfungsi, ekonomis, efektif, efisien, dan berkelanjutan (Razif, 2018; Suprayitno \& Soemitro, 2018).

\section{Dampak Pembangunan}

Pembangunan merupakan upaya untuk mengelola dan memanfaatkan sumberdaya untuk meningkatkan kesejahteraan manusia. Pembangunan dikatakan dapat memberikan dampak penting apabila didalam prosesnya menyebabkan perubahan lingkungan yang sangat mendasar pada lingkungan yang mengalami proses pembangunan.

Peraturan Pemerintah Republik Indonesia No. 27 Tahun 2012 tentang Izin Lingkungan dan Undang-Undang Republik Indonesia Nomor 32 Tahun 2009 tentang Perlindungan dan Pengelolaan Lingkungan Hidup menyatakan bahwa setiap kegiatan pembangunan yang dapat menimbulkan dampak bagi lingkungan perlu dilengkapi dengan analisis mengenai dampak lingkungan hidup (AMDAL) (PP 27/12; UU 32/09).

\section{Rona Lingkungan Awal}

Rona lingkungan merupakan kondisi lingkungan pada saat ini yaitu kondisi alam atau komponen-komponen lingkungan awal sebelum perencanaan dan pembangunan fisik dimulai. 
Rona lingkungan merupakan kondisi lingkungan awal sebelum tersentuh oleh kegiatan untuk keperluan perencanaan, konstruksi (pembangunan fisik) dan kegiatan operasi. Hal-hal yang termuat di dalam rona lingkungan antara lain komponen fisik - kimia lingkungan, komponen biologi, komponen sosial ekonomi dan budaya, dan komponen kesehatan masyarakat (UU 32/09).

\section{Proyek Konstruksi}

Pengertian proyek konstruksi menurut Ervianto (2005), adalah merupakan suatu rangkaian kegiatan yang hanya satu kali dilaksanakan dan umumnya berjangka waktu pendek. Proyek konstruksi dapat dibedakan menjadi dua jenis kelompok bangunan, yaitu bangunan gedung dan bangunan sipil.

\section{METODE PENELITIAN}

Secara administrasi, lokasi penelitian terletak di Jalan Mawar No. 9, Mekarsari, Kec. Cimanggis, Kota Depok, Jawa Barat. Bahan yang digunakan dalam penelitian ini antara lain data primer yang diperoleh secara langsung dari lapangan dan data sekunder yang diperoleh dengan cara pencarian data ke instansi dan pengujian laboratorium. Alat yang digunakan pada penelitian ini meliputi alat tulis, kamera, alat ukur survei, komputer, printer, dan kertas A4.

Metode yang digunakan dalam penelitian ini berupa metode survei. Data yang dikumpulkan berupa data primer dan data sekunder. Tahapan penelitian yang pertama dilakukan adalah studi pustaka yaitu kegiatan yang berkenaan dengan pengumpulan data pustaka. Tahapan kedua berupa pengumpulan data primer dan sekunder. Tahapan ketiga berupa pengolahan data. Tahap selanjutnya dilakukan analisa pengelompokan dampak lingkungan. Diagram alir penelitian disajikan pada Gambar 1 berikut.

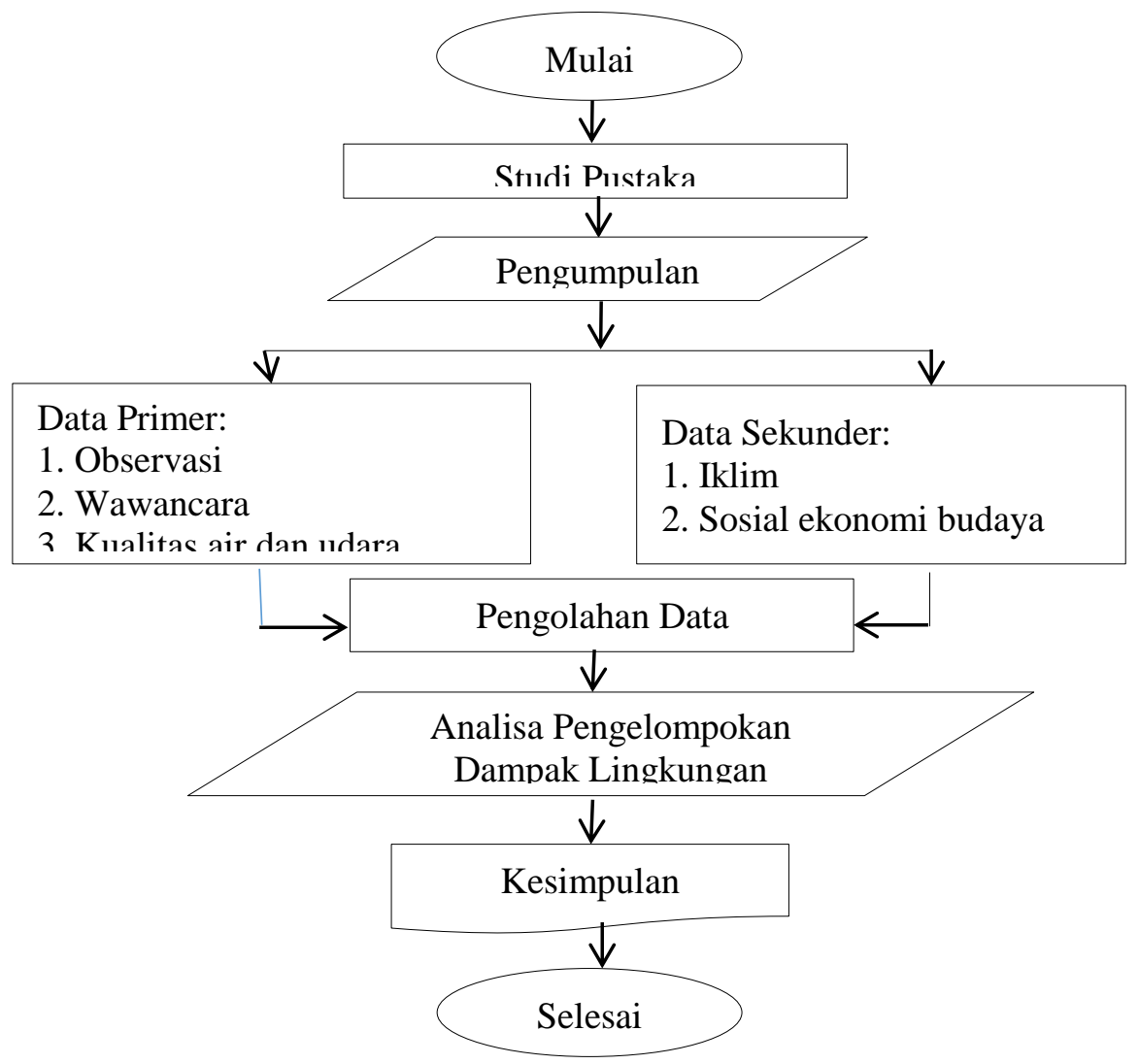

Gambar 1. Diagram Alir Penelitian 
Rekonstruksi Gedung Sekolah Dasar Negeri Mekarsari 6, Kota Depok akan dilakukan diatas tanah milik Pemerintah Kota Depok yang akan dibangun di atas lahan seluas $1568 \mathrm{~m}^{2}$, dengan total luas bangunan $880 \mathrm{~m}^{2}$. Peta Lokasi Penelitian disajikan pada Gambar 2 berikut.

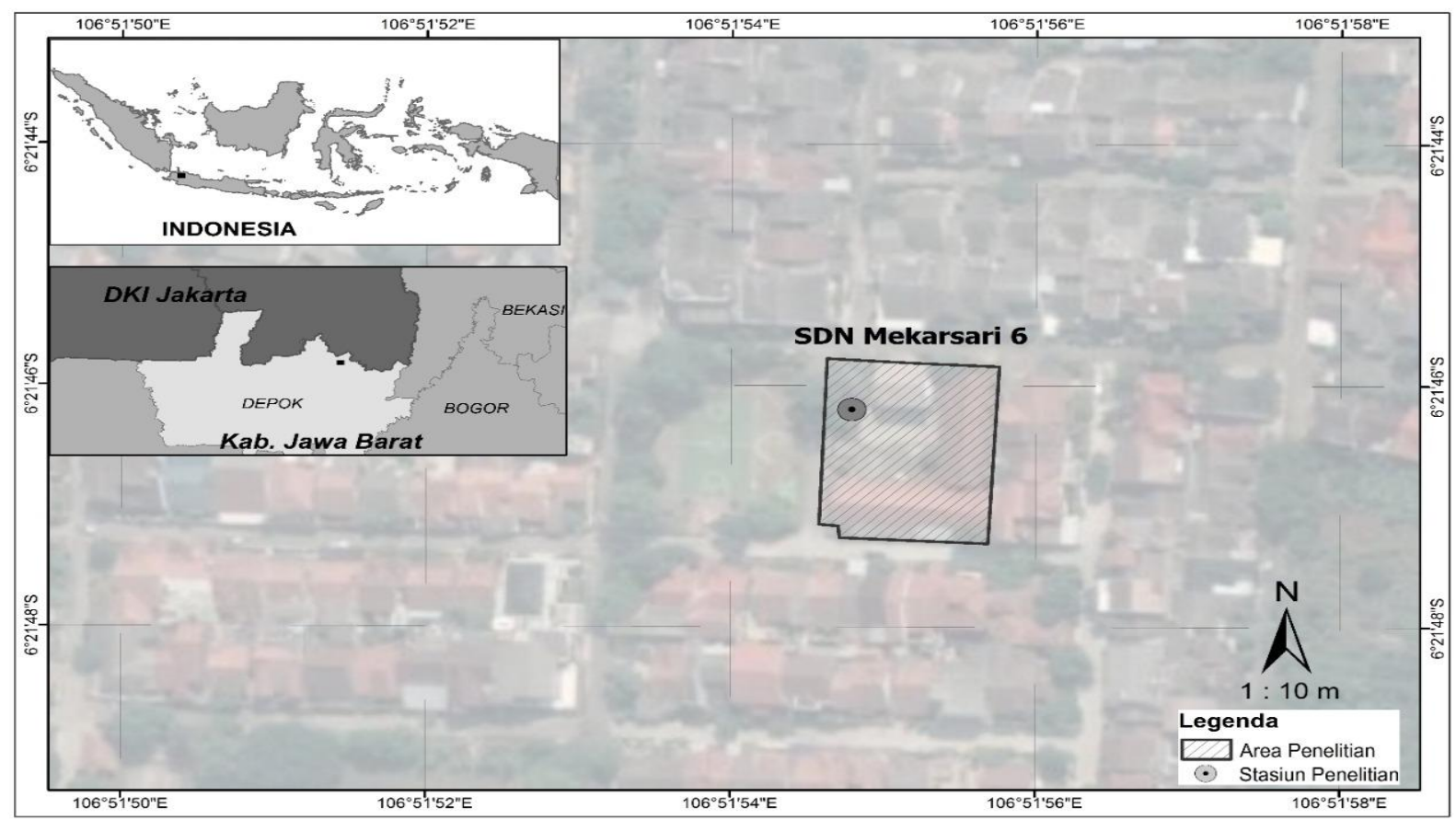

Gambar 2. Peta Lokasi Penelitian

\section{ANALISIS PENELITIAN}

\section{Komponen Fisik Kimia}

Komponen fisik kimia yang diamati meliputi curah hujan, hari hujan, suhu udara, Kelembapan udara, arah angin, kecepatan angin, dan lama penyinaran matahari.

Jumlah curah hujan tahunan rata-rata adalah sebesar $14 \mathrm{~mm} /$ bulan dengan curah hujan terendah terjadi pada bulan maret yaitu $7 \mathrm{~mm}$, sedangkan curah hujan tertinggi terjadi pada bulan mei yaitu sebesar $22 \mathrm{~mm}$. Dari data ini diketahui bahwa di lokasi penelitian terjadi curah hujan sepanjang tahun dan hampir tidak ada musim kemarau yang berarti, sehingga dapat disimpulkan bahwa di lokasi penelitian tidak mempunyai bulan kering.

Suhu udara di lokasi penelitian berkisar antara $25,6{ }^{\circ} \mathrm{C}-26,6{ }^{\circ} \mathrm{C}$ dengan rata- rata sebesar $26,1^{\circ} \mathrm{C}$, umumnya suhu udara tahunan rata-rata memiliki pola dengan suhu bulanannya. Pola suhu udara minimum terjadi pada bulan-bulan basah sedangkan pola suhu udara maksimum biasanya meningkat menjelang bulan-bulan kering.

Kelembapan udara di lokasi penelitian berkisar antara 74,5 \% - $85 \%$ dengan rata-rata tahunan sebesar $75 \%$. Kelembapan udara tertinggi terjadi pada bulan-bulan basah, sedangkan Kelembapan udara terendah terjadi pada bulan-bulan kering. Fluktuasi Kelembapan udara bulanan di lokasi penelitian relatif kecil dan tidak terdapat perubahan yang bersifat khusus (ekstrim). Kelembapan udara tersebut termasuk Kelembapan nisbi yang masih ditoleransi $(80 \%-90 \%)$. Data iklim di lokasi penelitian disajikan pada Tabel 1 berikut. 
Tabel 1. Data Iklim Di Lokasi Penelitian

\begin{tabular}{|c|c|c|c|c|c|c|}
\hline Bulan & $\begin{array}{c}\text { Curah Hujan } \\
\text { (mm) }\end{array}$ & $\begin{array}{l}\text { Temperatur } \\
\text { Udara }\left({ }^{\circ} \mathbf{C}\right)\end{array}$ & $\begin{array}{c}\text { Kelembaban } \\
\text { Udara }(\%)\end{array}$ & $\begin{array}{c}\text { Arah } \\
\text { Angin }\end{array}$ & $\begin{array}{c}\text { Kecepatan } \\
\text { Angin }(m / s)\end{array}$ & $\begin{array}{c}\text { Panjang } \\
\text { Penyinaran } \\
\text { Matahari (jam) } \\
\end{array}$ \\
\hline$\overline{\text { Januari }}$ & 8 & 25,7 & 82 & Utara & 2 & 2,4 \\
\hline Februari & 15 & 25,6 & 85 & Utara & 2 & 3,7 \\
\hline Maret & 7 & 26 & 83 & Utara & 1 & 5,1 \\
\hline April & 19 & 26,3 & 85 & Utara & 1,5 & 5,9 \\
\hline Mei & 22 & 26,6 & 82 & Utara & 1,5 & 7,3 \\
\hline Juni & 19 & 26,2 & 82,5 & Utara & 1 & 6,2 \\
\hline Juli & 9 & 25,8 & 76 & Utara & 1 & 8,5 \\
\hline Agustus & 7 & 25,9 & 74.5 & Utara & 2 & 7,9 \\
\hline September & 14 & 26,1 & 75 & Utara & 2 & 7,5 \\
\hline Oktober & 13 & 26,6 & 80 & Utara & 1 & 7 \\
\hline November & 20 & 26,4 & 83 & Utara & 1 & 4,8 \\
\hline Desember & 15 & 26,2 & 84 & Utara & 2 & 4,5 \\
\hline Rerata & 14 & 26,1 & 75 & Utara & 2 & 5,9 \\
\hline
\end{tabular}

Sumber: Kecamatan Cimanggis Dalam Angka, 2019

Arah angin di lokasi penelitian adalah seragam yaitu dengan arah angin bertiup ke arah utara. Kecepatan angin berkisar antara $1 \mathrm{~m} / \mathrm{s}-2 \mathrm{~m} / \mathrm{s}$ dengan kecepatan rata-rata tahunan sebesar $2 \mathrm{~m} / \mathrm{s}$. Arah angin dan kecepatan angin sangat mempengaruhi pola distribusi polutan penyebab pencemaran udara yang akan tersebar di sekitar lokasi penelitian.

Lama penyinaran matahari di lokasi penelitian berkisar antara 2,4 jam - 8,5 jam, dengan rata-rata 5,9 jam. Penyinaran matahari terendah terjadi pada bulan januari, sedangkan penyinaran matahari tertinggi terjadi pada bulan-bulan relatif kering dengan puncaknya pada bulan Juli.

\section{Komponen Biologi}

Semakin tinggi keanekaragaman jenis flora dan fauna, maka semakin tinggi pula tingkat kelestarian lingkungan biologinya atau semakin kecil tingkat pencemarannya. Demikian juga sebaliknya. Jenis vegetasi yang ada di wilayah lokasi penelitian pada umumnya berupa tanaman jenis bunga dan pohon mangga. Jenis fauna yang ada di wilayah lokasi lokasi penelitian pada umumnya berupa satwa peliharaan yang sering dijumpai yaitu: kucing, ayam, dan anjing.

\section{Komponen Udara Ambien dan Kebisingan}

Pengambilan sampel udara ambien menggunakan alat impinger sedangkan pengukuran kebisingan menggunakan alat Sound Level Meter. Pengukuran kualitas udara ambien dan kebisingan dilakukan di dua lokasi yaitu lokasi penelitian (UA-1) dan di sekitar pemukiman masyarakat (UA-2). Hasil samping dianalisis di laboratorium yang terakreditasi. Hasil analisis laboratorium kualitas udara ambien dan kebisingan disajikan pada Tabel 2 berikut. 
Tabel 2. Hasil Analisis Laboratorium Kualitas Udara Ambien dan Kebisingan

\begin{tabular}{|c|c|c|c|c|c|}
\hline \multirow{2}{*}{ No } & \multirow{2}{*}{ Test Description } & \multirow{2}{*}{$\begin{array}{c}\text { Regulatory } \\
\text { Limit ** }\end{array}$} & \multirow{2}{*}{ Unit } & \multicolumn{2}{|c|}{ Sample Result } \\
\hline & & & & UA-1 & UA-2 \\
\hline \multicolumn{6}{|c|}{ Ambient Air Quality: } \\
\hline 1 & Sulfur Dioxide, $\mathrm{SO}_{2}$ & $900 / 1 \mathrm{H}$ & $\mu \mathrm{g} / \mathrm{Nm}^{3}$ & $<47.9$ & $<47.9$ \\
\hline 2 & Carbon Monoxide, $\mathrm{CO}$ & $30000 / 1 \mathrm{H}$ & $\mu \mathrm{g} / \mathrm{Nm}^{3}$ & 470 & 520 \\
\hline 3 & Nitrogen Dioxide, $\mathrm{NO}_{2}$ & $400 / 1 \mathrm{H}$ & $\mu \mathrm{g} / \mathrm{Nm}^{3}$ & 28,43 & 30,28 \\
\hline 4 & Oxidant, $\mathrm{O}_{3}$ & $235 / 1 \mathrm{H}$ & $\mu \mathrm{g} / \mathrm{Nm}^{3}$ & $<48.3$ & $<48.3$ \\
\hline 5 & Dust, Particulate & $230 / 24 \mathrm{H}$ & $\mu \mathrm{g} / \mathrm{Nm}^{3}$ & 30,5 & 32,5 \\
\hline \multicolumn{6}{|c|}{ Odor Air Quality : } \\
\hline 1 & Ammonia, $\mathrm{NH}_{3} *$ & $2 \cdot$ & ppm & $<0.024$ & 0,026 \\
\hline \multirow[t]{2}{*}{2} & Hydrogen Sulfide, $\mathrm{H}_{2} \mathrm{~S}^{*}$ & $0.02 \bullet$ & $\mathrm{ppm}$ & $<0.004$ & $<0.004$ \\
\hline & Noise : & & & & \\
\hline 1 & Kebisingan Ekuivalen, Leq & $55-70$ & $\mathrm{~dB}(\mathrm{~A})$ & 44,8 & 50,4 \\
\hline 2 & Kebisingan Minimum, $\mathrm{L}_{\min }$ & & & 42,5 & 48,6 \\
\hline 3 & Kebisingan Maksimum, $\mathrm{L}_{\max }$ & & & 47,1 & 52,1 \\
\hline \multicolumn{6}{|c|}{ - (**) Ambient Air Standard Quality Regulation, PPRI No. $41 / 1999$} \\
\hline \multicolumn{6}{|c|}{ - The test results relate only to the items tested } \\
\hline \multicolumn{6}{|c|}{ - References sampling SNI 19.7119.6 - 2005} \\
\hline 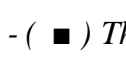 & 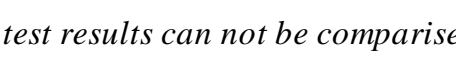 & & & & \\
\hline
\end{tabular}

Meteorology Data

\begin{tabular}{llccc} 
No & \multicolumn{1}{c}{ Description } & Unit & UA-1 & Result \\
1 & Temperature & ${ }^{\circ} \mathrm{C}$ & 32,3 & UA-2 \\
2 & Relative Humidity & $\%$ & 55,8 & 33,9 \\
3 & Wind Speed & $\mathrm{m} / \mathrm{s}$ & $0,2-0,8$ & 50,1 \\
4 & Wind Direction & - & $\mathrm{B}-\mathrm{T}$ & $0,3-1,1$ \\
\end{tabular}

Dari data pada tabel 2 tampak bahwa arah angin dominan yang tercatat yaitu ke arah timur dengan kecepatan berkisar antara 0,2-1,1 m/s. Kualitas udara ambien di lokasi rencana kegiatan dan sekitarnya masih baik, mengingat parameter-parameter yang terukur masih memenuhi baku mutu lingkungan (BML) sesuai dengan Peraturan Pemerintah Nomor 41 Tahun 1999 untuk $\mathrm{SO}_{2}, \mathrm{NO}_{2}$, TSP, $\mathrm{CO}$, dan $\mathrm{O}_{3}$, Keputusan Menteri Negara Lingkungan Hidup Nomor 50 Tahun 1996 untuk $\mathrm{H}_{2} \mathrm{~S}$ dan $\mathrm{NH}_{3}$, dan Peraturan Pemerintah Republik Indonesia Nomor 41 Tahun 1999 tentang Baku Mutu Udara Ambien Nasional (PP 41/99; KepMen LH 50/96).

Hasil pengukuran tingkat kebisingan rata-rata di lokasi penelitian sebesar 44,8 db(A) dan 50,4 db(A). Berdasarkan Keputusan Menteri Negara Lingkungan Hidup Nomor 48 Tahun 1996 tentang Baku Tingkat Kebisingan, hasil pengukuran kebisingan berada di bawah baku mutu yang dipersyaratkan (KepMen LH 48/96).

\section{Komponen Air Tanah}

Pengukuran kualitas air tanah dilakukan di dua lokasi yaitu rencana lokasi penelitian (AT1) dan di sekitar pemukiman masyarakat (AT-2). Hasil samping dianalisis di laboratorium yang terakreditasi. Hasil pengukuran insitu dan analisis laboratorium secara ringkas disajikan pada Tabel 3 berikut. 
(e)ISSN 2615-1847 (p)ISSN 2615-1839

Jurnal Manajemen Aset Infrastruktur \& Fasilitas - Vol.5, No.1, Januari 2021

Tabel 3. Hasil Analisis Laboratorium Kualitas Air Tanah

\begin{tabular}{|c|c|c|c|c|c|}
\hline \multirow{2}{*}{ No } & \multirow{2}{*}{ Test Description } & \multicolumn{2}{|c|}{ Sample Result } & \multirow{2}{*}{$\begin{array}{l}\text { Regulatory } \\
\text { Limit** }\end{array}$} & \multirow{2}{*}{ Unit } \\
\hline & & AT-1 & AT-2 & & \\
\hline & Physical Properties: & & & & \\
\hline 1 & Turbidity* & 0,01 & 0,2 & 25 & NTU \\
\hline 2 & Color* & $<1$ & $<1$ & 50 & TCU \\
\hline 3 & Total Dissolved Solid, TDS* & 159 & 98 & 1000 & $\mathrm{mg} / \mathrm{l}$ \\
\hline 4 & Temperature $*$ & 28,5 & 28,5 & Suhu udara \pm 3 & - \\
\hline 5 & Taste & Tidak berasa & Tidak berasa & Tidak berasa & - \\
\hline \multirow[t]{2}{*}{6} & Odor & Tidak berbau & Tidak berbau & Tidak berbau & - \\
\hline & Chemical Anorganic Properties: & & & & \\
\hline 1 & $\mathrm{pH} \bullet *$ & 6,55 & 6,59 & $6.5-8.5$ & $\mathrm{mg} / \mathrm{l}$ \\
\hline 2 & Iron, $\mathrm{Fe}^{*}$ & 0,042 & $<0.013$ & 1 & $\mathrm{mg} / \mathrm{l}$ \\
\hline 3 & Hardness Total as $\mathrm{CaCO}_{3} *$ & 84,13 & 53,54 & 500 & $\mathrm{mg} / \mathrm{l}$ \\
\hline 4 & Manganese, $\mathrm{Mn}^{*}$ & 0,016 & 0,018 & 0,5 & $\mathrm{mg} / \mathrm{l}$ \\
\hline 5 & Nitrogen, Nitrate as $\mathrm{N}\left(\mathrm{NO}_{3}-\mathrm{N}\right)^{*}$ & 0,112 & 0,109 & 10 & $\mathrm{mg} / \mathrm{l}$ \\
\hline 6 & Nitrogen, Nitrite as $\mathrm{N}\left(\mathrm{NO}_{2}-\mathrm{N}\right)^{*}$ & 0,007 & 0,008 & 1 & $\mathrm{mg} / \mathrm{l}$ \\
\hline 7 & Mercury, $\mathrm{Hg}^{*}$ & $<0.00009$ & $<0.00009$ & 0,001 & $\mathrm{mg} / \mathrm{l}$ \\
\hline 8 & Arsenic, As & $<0.00006$ & $<0.00006$ & 0,05 & $\mathrm{mg} / \mathrm{l}$ \\
\hline 9 & Chromium hexavalent, $\mathrm{Cr}^{6+*}$ & $<0.001$ & $<0.001$ & 0,05 & $\mathrm{mg} / \mathrm{l}$ \\
\hline 10 & Zinc, $\mathrm{Zn}^{*}$ & 0,123 & 0,032 & 15 & $\mathrm{mg} / \mathrm{l}$ \\
\hline 11 & Sulphate, $\mathrm{SO}_{4}{ }^{2-*}$ & 4,13 & 1,88 & 400 & - \\
\hline \multirow[t]{2}{*}{12} & Lead, $\mathrm{Pb}^{*}$ & $<0.0002$ & $<0.0002$ & 0,05 & $\mathrm{mg} / \mathrm{l}$ \\
\hline & Biological Properties: & & & & \\
\hline 1 & Total Coliform & 2 & 6 & 50 & $\mathrm{CFU} / 100 \mathrm{ml}$ \\
\hline 2 & E. Coli & $<1.8$ & $<1.8$ & 0 & $\mathrm{CFU} / 100 \mathrm{ml}$ \\
\hline \multicolumn{6}{|c|}{ - (*) Accreditade by KAN } \\
\hline \multicolumn{6}{|c|}{ - (**) Clean Water Standard Quality Regulation, PerMenKes No. 32/2017 } \\
\hline \multicolumn{6}{|c|}{ - The test results relate only to the items tested } \\
\hline Refere & sampling SNI 989.58:2008 & & & & \\
\hline
\end{tabular}

Berdasarkan data hasil analisis kualitas air tanah pada tabel 3, terlihat bahwa semua parameter memenuhi baku mutu yang ditetapkan menurut Peraturan Menteri Kesehatan Nomor 32 Tahun 2017 Tentang Standar Baku Mutu Kesehatan Lingkungan dan Persyaratan Kesehatan Air Untuk Keperluan Higiene Sanitasi, Kolam Renang, Solus Per Aqua, dan Pemandian Umum (PerMenKes 32/17)

\section{Komponen Sosial Ekonomi dan Budaya}

\section{Mata Pencaharian}

Mata pencaharian yang dilakoni masyarakat di lokasi penelitian adalah sebagian besar berprofesi sebagai pegawai swasta yaitu sebanyak 10.689 orang $(57,7 \%)$ dan berwiraswasta yaitu sebanyak 3.246 orang $(17,52 \%)$. Sebaran mata pencaharian penduduk di lokasi penelitian disajikan pada Tabel 4 berikut. 
Tabel 4. Sebaran Mata Pencaharian Penduduk di Lokasi Penelitian

\begin{tabular}{clcc}
\hline No & \multicolumn{1}{c}{ Matapencaharian } & Jumlah & \% \\
\hline 1 & Pertanian & 5 & 0,03 \\
2 & Wiraswasta/pedagang & 3.246 & 17,52 \\
3 & Informal & 345 & 1,86 \\
4 & Buruh & 1.269 & 6,85 \\
5 & PNS/TNI/POLRI & 1.158 & 6,25 \\
6 & Pensiunan & 731 & 3,95 \\
7 & Pegawai Swasta & 10.689 & 57,7 \\
8 & Lainnya $\quad 1.083$ & 5,85 \\
& & $\mathbf{1 8 . 5 2 6}$ & $\mathbf{1 0 0}$ \\
\hline
\end{tabular}

Sumber: BPS Kota Depok, 2019

\section{Pendapatan Rumah Tangga}

Masyarakat di lokasi penelitian memiliki pendapatan dari pekerjaan utama dan pekerjaan sampingan. Besarnya pendapatan masyarakat seringkali fluktuatif, dan bahkan sebagian responden tidak dapat menghitung secara pasti pendapatannya, ada pula yang tidak bersedia menjawab. Berdasarkan wawancara terhadap responden, diperoleh nilai rentang pendapatan masyarakat disajikan pada Tabel 5 berikut.

Tabel 5. Penghasilan Masyarakat dari Pekerjaan Utama di Lokasi Penelitian

\begin{tabular}{clc}
\hline No & \multicolumn{1}{c}{ Penghasilan $(\mathrm{Rp})$} & Persentase $(\%)$ \\
\hline 1 & $\leq 1.000 .000$ & 14,25 \\
2 & $1.000 .000-3.000 .000$ & 52,44 \\
3 & $3.000 .001-5.000 .000$ & 26,33 \\
4 & $\geq 5.000 .000$ & 3,55 \\
5 & Tidak tentu & 1,21 \\
6 & Tidak menjawab & 2,22 \\
Total: & & $\mathbf{1 0 0}$ \\
\hline
\end{tabular}

Sumber: Survei Team, 2019

Berdasarkan tabel diatas terlihat bahwa 52,44\% penghasilan responden terbesar adalah dari pekerjaan utamanya yang berkisar antara Rp. 1.000 .000 - Rp 3.000.000/bulan. Dari hasil pendapatan tersebut, warga membiayai pengeluaran untuk konsumsi dan non konsumsi, yaitu kebutuhan makan-minum, biaya pendidikan, biaya pemakaian listrik, biaya transportasi, biaya membeli sandang, biaya perawatan rumah tinggal, biaya perawatan alat transportasi, biaya pembelian alat rumah tangga, biaya wisata/piknik/hiburan dan biaya sosial serta cicilan hutang. Pengeluaran terbanyak dari jawaban responden adalah untuk memenuhi kebutuhan konsumsi sedangkan pengeluaran terkecil adalah untuk biaya perawatan alat transportasi.

\section{Persepsi dan Sikap Masyarakat}

Berdasarkan hasil wawancara yang dilakukan terhadap responden, pada umumnya responden mengetahui rencana pembangunan Gedung SDN Mekarsari 6 yang akan dibangun di wilayah mereka yaitu sebanyak $96 \%$. Tanggapan responden tentang informasi rencana kegiatan rekonstruksi gedung SDN Mekarsari 6, disajikan pada Tabel 6 berikut. 
Tabel 6. Tanggapan Responden Terhadap Kegiatan Rekonstruksi Gedung Sekolah

\begin{tabular}{|c|c|c|c|}
\hline No & Uraian & Jumlah (\%) & Keterangan \\
\hline \multirow{4}{*}{1} & Apakah Bapak/ibu sudah pernah mendengar renca & zunan SDN Me & 5 ini? \\
\hline & a. Ya & 96 & \\
\hline & b. Tidak & 4 & \\
\hline & Jumlah & 100 & \\
\hline \multirow{6}{*}{2} & Kalau ya, sumber informasi tersebut berasal dari n & & \\
\hline & a. Sosialisasi & 45 & \\
\hline & b. Kecamatan/kelurahan & 19 & \\
\hline & c. Tokoh Masyarakat & 15 & \\
\hline & d. Lainnya & 21 & Tetangga \\
\hline & Jumlah & 100 & \\
\hline \multirow{5}{*}{3} & Bagaimana tanggapan Bapak/Ibu mengenai renca & ersebut? & \\
\hline & a. Sangat setuju & 20 & \\
\hline & b. Setuju & 80 & \\
\hline & c. Tidak setuju & 0 & \\
\hline & Jumlah & 100 & \\
\hline \multirow{5}{*}{4} & Apa yang menjadi harapan Bapak/Ibu terkait renc & gunan SDN M & 6 ini? \\
\hline & a. Membuka kesempatan kerja & 40 & \\
\hline & b. Adanya peluang berusaha & 50 & \\
\hline & c. Kontribusi perusahaan bagi kemajuan wilayah & 10 & \\
\hline & Jumlah & 100 & \\
\hline \multirow{6}{*}{5} & Apa yang Bapak/Ibu khawatirkan dari rencana pe & SDN Mekarsa & \\
\hline & a. Polusi udara & 35 & \\
\hline & b. Meningkatnya kebisingan & 25 & \\
\hline & c. Terganggunya lalulintas (macet) & 25 & \\
\hline & d. Lainnya & 15 & \\
\hline & Jumlah & 100 & \\
\hline
\end{tabular}

Sumber: Survei Team, 2019

\section{Komponen Kesehatan Masyarakat}

\section{Sarana Kesehatan dan Pelayanan Kesehatan Masyarakat}

Pada dasarnya pembangunan dibidang kesehatan bertujuan untuk memberikan pelayanan kesehatan secara mudah, merata dan murah. Salah satu upaya pemerintah dalam rangka memeratakan pelayanan kesehatan kepada masyarakat adalah dengan menyediakan fasilitas kesehatan, terutama puskesmas dan puskesmas pembantu karena kedua fasilitas tersebut dapat menjangkau segala lapisan masyarakat hingga ke daerah terpencil. Salah satu indikator kesejahteraan penduduk suatu daerah adalah kondisi kesehatan masyarakat. Fasilitas kesehatan di Desa Mekarsari yang tersedia yaitu 2 unit rumah sakit, 1 unit puskesmas, 23 unit posyandu, 1 unit pos KB, dan 2 unit klinik.

\section{Air Bersih dan Sanitasi Lingkungan}

Air bersih merupakan kebutuhan yang sangat penting bagi rumah tangga dalam kehidupan sehari-hari, ketersediaan dalam jumlah yang cukup terutama untuk keperluan minum dan memasak merupakan tujuan program penyediaan air bersih yang diupayakan terus menerus oleh pemerintah.

Akses masyarakat kelurahan di lokasi penelitian terhadap air minum yang sehat tergolong cukup baik. Berdasarkan hasil wawancara terhadap responden yang dilakukan, rumah tangga 
terhadap akses air minum/bersih berasal dari dari air sumur gali/sumur pompa dan berasal dari PDAM, dan sementara sumber air untuk minum sebagian berasal dari air kemasan/galon.

Kondisi rona awal sanitasi lingkungan masyarakat di lokasi penelitian sudah mencerminkan sanitasi lingkungan masyarakat modern. Perilaku sebagian besar masyarakat terhadap pengelolaan kesehatan lingkungan sudah dilakukan sesuai dengan standar pengelolaan yang dianjurkan dan standar hidup sehat, seperti membuang sampah pada tempatnya dan menggunakan air bersih untuk mandi dan mencuci.

\section{Dampak Lingkungan Yang Ditimbulkan dan Cara Meminimalisir Dampak}

Dampak dari Kegiatan Rekonstruksi Gedung Sekolah SDN 6 Mekarsari, Kota Depok berpengaruh pada aspek komponen lingkungan fisik-kimia dan sosial ekonomi budaya masyarakat setempat. Adapun uraian mengenai sumber dampak, jenis dampak, besaran dampak, dan cara meminimalisir dampak disajikan pada Tabel 7 berikut. Dampak Lingkungan dianalisis untuk kondisi-kondisi Tahap Pra Konstruksi, Tahap Konstruksi dan Tahap Operasi.

Aspek yang penting untuk tahap Pra Konstruksi terutama terkait dengan persepsi masyarakat, penurunan kualitas udara, dan peningkatan kebisingan. Hal-hal yang harus dilakukan untuk meminimalisir dampak adalah: berkoordinasi dengan tokoh dan otoritas setempat, membangun pagar proyek, melakukan pembongkaran dengan teknik yang baik, serta menggunakan cara pengangkutan angkut yang baik.

Aspek penting bagi Tahap Konstruksi adalah adanya peluang kerja dan peningkatan pendapatan masyarakat, penurunan kualitas udara (sebaran debu lokal), peningkatan air larian, dan kekeruhan saluran drainase. Hal-hal yang seyogyanya dilakukan adalah memeberi prioritas bagi warga sekitar untuk ikut bekerja di proyek, mengatur pengangkutan proyek, membuat sumur resapan, serta membuat sediment trap di saluran drainase.

Aspek pentng bagi tahap Operasi adalah terjadinya kerusakan jalan dan kemacetan lalulintas, kerusakan drainase, penurunan muka air tanah dangkal, serta terciptanya peluang kerja, peluang usaha baru. Hal-hal yang harus dikerjakan adalah mengikut saran andal lalin, penanganan sampah yang baik, menanam pohon dan memaksimalkan lahan bukaan, membuat sumur resapan, serta memberi keseempatan warga setempat untuk membuka usaha terkait disekitar proyek. 
Tabel 7. Sumber Dampak, Jenis Dampak, Besaran Dampak, dan Cara Meminimalisir Dampak Rencana Kegiatan Rekonstruksi Gedung Sekolah

\begin{tabular}{|c|c|c|c|}
\hline Sumber Dampak & Jenis Dampak & Besaran Dampak & Cara Meminimalisir Dampak \\
\hline \multicolumn{4}{|c|}{$\begin{array}{l}\text { Tahap Pra konstruksi } \\
\text { A. Perubahan Persepsi Masyarakat, Penurunan Kualitas Udara dan Peningkatan Kebisingan. }\end{array}$} \\
\hline $\begin{array}{l}\text { Dilakukannya } \\
\text { sosialisasi perencanaan } \\
\text { dan persiapan } \\
\text { pembongkaran gedung } \\
\text { lama pada lokasi } \\
\text { penelitian Gedung } \\
\text { Sekolah SDN } \\
\text { Mekarsari 6. }\end{array}$ & $\begin{array}{l}\text { Jenis dampak yang } \\
\text { ditimbulkan adalah } \\
\text { perubahan persepsi } \\
\text { masyarakat, penurunan } \\
\text { kualitas udara dan } \\
\text { peningkatan } \\
\text { kebisingan. }\end{array}$ & $\begin{array}{l}\text { Parameter kualitas } \\
\text { udara yang } \\
\text { diperkirakan akan } \\
\text { meningkat di } \\
\text { antaranya adalah } \\
\mathrm{NO}_{2}, \mathrm{CO} \text {, debu } \\
(\mathrm{TSP}), \mathrm{NH}_{3} \text {, dan } \\
\mathrm{H}_{2} \mathrm{~S}, \text { peningkatan } \\
\text { kebisingan dan } \\
\text { keresahan } \\
\text { masyarakat. }\end{array}$ & $\begin{array}{l}\varnothing \text { Membina hubungan baik dengan } \\
\text { tokoh masyarakat, instansi yang } \\
\text { berwenang di sekitar lokasi } \\
\text { kegiatan. } \\
\varnothing \text { Membatasi kegiatan } \\
\text { pembongkaran tidak dilakukan pada } \\
\text { malam hari. } \\
\varnothing \text { Menggunakan kendaraan material } \\
\text { yang layak jalan. } \\
\varnothing \text { Kendaraan pengangkut material } \\
\text { dilengkapi dengan terpal penutup } \\
\text { yang baik. } \\
\varnothing \text { Membuat pagar pelindung di } \\
\text { sekeliling tapak proyek sebagai } \\
\text { windbreak untuk meredam } \\
\text { kebisingan, mengisolir gas-gas, } \\
\text { debu, dan polutan sehingga tidak } \\
\text { terbawa angin ke lokasi lain. }\end{array}$ \\
\hline $\begin{array}{l}\text { Tahap Konstruksi } \\
\text { A. Peluang Kerja da }\end{array}$ & in Peni & & \\
\hline $\begin{array}{l}\text { Bersumber dari } \\
\text { kegiatan penerimaan } \\
\text { tenaga kerja lokal, } \\
\text { peluang kesempatan } \\
\text { kerja dan usaha bagi } \\
\text { penduduk setempat. }\end{array}$ & $\begin{array}{l}\text { Dampak yang } \\
\text { ditimbulkan bersifat } \\
\text { positif sebab dapat } \\
\text { memberikan peluang } \\
\text { kerja sehingga } \\
\text { diharapkan akan } \\
\text { meningkatkan } \\
\text { pendapatan bagi } \\
\text { penduduk setempat. }\end{array}$ & $\begin{array}{l}\text { Memberikan } \\
\text { kesempatan kerja dan } \\
\text { peluang berusaha } \\
\text { kepada masyarakat } \\
\text { sekitar lokasi } \\
\text { penelitian }\end{array}$ & $\begin{array}{l}\emptyset \text { Pemberitahuan kepada warga } \\
\text { bahwa rekonstruksi gedung sekolah } \\
\text { membutuhkan tenaga kerja pada } \\
\text { tahap konstruksi dan kemudian } \\
\text { mengadakan seleksi dan penerimaan } \\
\text { tenaga kerja. } \\
\varnothing \text { Membuka kesempatan bagi } \\
\text { warga untuk dapat membuka usaha } \\
\text { seperti rumah makan atau kios kecil } \\
\text { untuk memenuhi kebutuhan para } \\
\text { pekerja konstruksi. }\end{array}$ \\
\hline
\end{tabular}


Tabel 7. Sumber Dampak, Jenis Dampak, Besaran Dampak, dan Cara Meminimalisir Dampak Rencana Kegiatan Rekonstruksi Gedung Sekolah (Lanjutan)

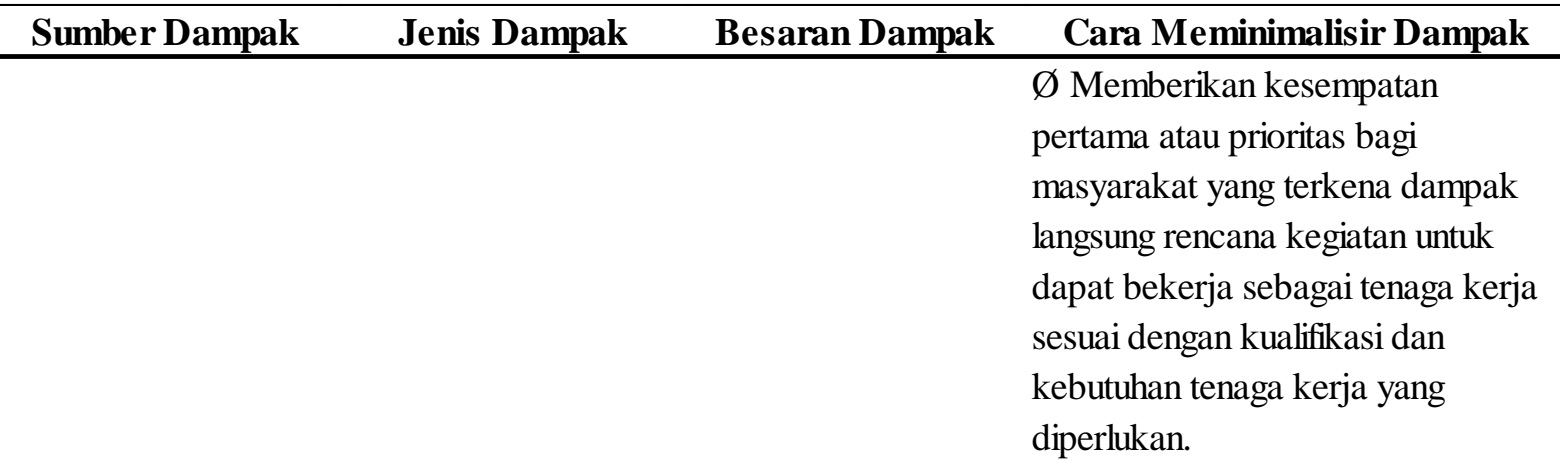

\section{B. Penurunan Kualitas Udara (Sebaran Debu Lokal)}

Berasal dari kegiatan Bersifat negatif karena Terjadinya penurunan mobilisasi alat dan dapat menimbulkan kualitas udara ambien material dan adanya penurunan kualitas di sekitar lokasi limbah padat dari udara yang dapat penelitian menurut bongkaran bangunan mengganggu kesehatan Peraturan Pemerintah lama. dan nilai estetika lingkungan, sehingga akan menimbulkan kerawanan sosial.

\section{No. 41 tahun 1999}

tentang Pengendalian

Pencemaran Udara. $\varnothing$ Membatasi kecepatan kendaraan pengangkut alat dan bahan material saat memasuki lokasi penelitian

\section{$\varnothing$ Menutup bak kendaraan}

pengangkut alat dan bahan material

dengan kain plastik atau terpal,

terutama batu urug, sehingga tidak

terjadi ceceran bahan material yang diangkut

\section{Peningkatan Air Larian (Run Off) dan Terjadinya Kekeruhan Saluran Drainase}

Dari kegiatan Bersifat negatif yaitu Meningkatnya volume $\varnothing$ Membuat saluran drainase yang pembangunan sarana berupa peningkatan air air larian di sekitar dan prasarana baru, larian (run off) akibat gedung sekolah. perataan dan penurunan kapasitas pematangan lahan yang infiltrasi ke tanah dari akan dilakukan adanya rekonstruksi pembangunan serta pasar (tutupan lahan) memadai yang menyesuaikan dengan debit air larian.

$\varnothing$ Membuat sumur-sumur resapan. $\varnothing$ Membuat sedimen trap sebelum saluran drainase pasar.

Tahap Operasi

\section{A.Kerusakan Jalan dan Kemacetan Lalu Lintas}

\begin{tabular}{|c|c|c|c|}
\hline $\begin{array}{l}\text { Dari kegiatan } \\
\text { operasional gedung } \\
\text { sekolah yaitu } \\
\text { penggunaan kendaraan } \\
\text { pengunjung maupun } \\
\text { pekerja di gedung } \\
\text { sekolah. }\end{array}$ & $\begin{array}{l}\text { Dampak yang } \\
\text { ditimbulkan bersifat } \\
\text { negatif karena } \\
\text { kerusakan jalan dan } \\
\text { kemacetan lalu lintas. }\end{array}$ & $\begin{array}{l}\text { Rusaknya jalan dan } \\
\text { terjadinya kemacetan } \\
\text { lalu lintas. }\end{array}$ & $\begin{array}{l}\varnothing \text { Pemasangan perlengkapan jalan } \\
\text { seperti rambu lalu lintas dan marka } \\
\text { jalan sesuai kebutuhan serta fasilitas } \\
\text { penyeberangan berupa zebracross. } \\
\varnothing \text { Mengikuti dan mematuhi saran } \\
\text { teknis lalu lintas yang diberikan oleh } \\
\text { instansi terkait. } \\
\varnothing \text { Menyediakan satuan pengamanan } \\
\text { untuk mengatur lalu lintas kendaraan } \\
\text { tamu di pintu masuk/keluar. }\end{array}$ \\
\hline
\end{tabular}


Tabel 7. Sumber Dampak, Jenis Dampak, Besaran Dampak, dan Cara Meminimalisir Dampak Rencana Kegiatan Rekonstruksi Gedung Sekolah (Lanjutan)

\begin{tabular}{|c|c|c|c|}
\hline Sumber Dampak & Jenis Dampak & Besaran Dampak & Cara Meminimalisir Dampak \\
\hline \multicolumn{4}{|c|}{ B. Kerusakan Drainase } \\
\hline $\begin{array}{l}\text { Bersumber dari } \\
\text { aktifitas yang } \\
\text { meyebabkan timbulan } \\
\text { sampah yang tercecer } \\
\text { ke saluran drainase } \\
\text { yang menyebabkan } \\
\text { tersumbat dan } \\
\text { rusaknya saluran } \\
\text { drainase pasar }\end{array}$ & $\begin{array}{l}\text { Dampak yang } \\
\text { ditimbulkan bersifat } \\
\text { negatif karena } \\
\text { kerusakan drainase } \\
\text { akan menimbulkan } \\
\text { genangan. }\end{array}$ & $\begin{array}{l}\text { Peningkatan ceceran } \\
\text { sampah pada saluran } \\
\text { drainase sekitar } \\
\text { gedung sekolah. }\end{array}$ & $\begin{array}{l}\varnothing \text { Menyiapkan tempat sampah } \\
\text { pada setiap lantai dan memisahkan } \\
\text { antara sampah organik dan non } \\
\text { organik. } \\
\varnothing \text { Menyediakan dan membuang } \\
\text { sampah pada TPS sementara dan } \\
\text { mengangkutnya sesuai dengan } \\
\text { jadwal dan keperluan ke TPA yang } \\
\text { bekerjasama dengan instansi terkait. }\end{array}$ \\
\hline $\begin{array}{l}\text { C. Penurunan Mul } \\
\text { Penggunaan air bersih } \\
\text { yang berasal dari air } \\
\text { tanah dangkal, } \\
\text { sehingga ketersediaan } \\
\text { air tanah dangkal } \\
\text { menurun. }\end{array}$ & $\begin{array}{l}\text { Air Tanah Dangkal } \\
\text { Bersifat negatif, karena } \\
\text { penurunan muka air } \\
\text { tanah berpotensi } \\
\text { menyebabkan } \\
\text { kekeringan air tanah } \\
\text { dangkal terutama pada } \\
\text { saat musim kemarau. }\end{array}$ & $\begin{array}{l}\text { Menurunnya volume } \\
\text { muka air tanah } \\
\text { dangkal penduduk } \\
\text { sekitar gedung } \\
\text { sekolah. }\end{array}$ & $\begin{array}{l}\varnothing \text { Melakukan penghijauan pada } \\
\text { lokasi lahan terbuka yang tidak } \\
\text { dibangun. } \\
\varnothing \text { Membatasi penambahan tutupan } \\
\text { di lahan yang masih terbuka. } \\
\varnothing \text { Membatasi pemakaian air bersih } \\
\text { yang berasal dari tanah dangkal. } \\
\varnothing \text { Membuat sumur-sumur resapan. }\end{array}$ \\
\hline D. Terciptanya Pe & uang Kerja, Peluang & & conomian Lokal \\
\hline $\begin{array}{l}\text { Dari beroperasinya } \\
\text { gedung sekolah } \\
\text { memberikan peluang } \\
\text { untuk kerja, berusaha } \\
\text { yang dapat } \\
\text { meningkatkan } \\
\text { perekonomian lokal. }\end{array}$ & $\begin{array}{l}\text { Dampak yang } \\
\text { ditimbulkan bersifat } \\
\text { positif sebab akan } \\
\text { terciptanya peluang } \\
\text { kerja, peluang usaha } \\
\text { baru dan } \\
\text { perekonomian lokal }\end{array}$ & $\begin{array}{l}\text { Meningkatnya } \\
\text { pendapatan warga di } \\
\text { sekitar gedung } \\
\text { sekolah }\end{array}$ & $\begin{array}{l}\emptyset \text { Memberikan izin pada warga } \\
\text { sekitar untuk membuka usaha di } \\
\text { sekitar gedung sekolah. }\end{array}$ \\
\hline
\end{tabular}

\section{KESIMPULAN}

Berdasarkan hasil dan pembahasan analisa dampak lingkungan terhadap rekonstruksi gedung sekolah SDN Mekarsari 6, Kota Depok dapat disimpulkan sebagai berikut:

1. Rona awal lingkungan pada lokasi penelitian menunjukkan bahwa kualitas lingkungan di lokasi penelitian dalam kategori baik, baik dari segi komponen kualitas udara ambien dan kebisingan maupun komponen kualitas air tanah.

2. Diperolehnya suatu analisa dampak lingkungan yang terjadi dan cara untuk meminimalisir dampak negatif yang terjadi dan mengembangkan dampak positif dengan penanganan yang baik.

\section{DAFTAR PUSTAKA}

Alimuddin, dkk. (2020). "Kajian Dampak Lingkungan Terhadap Kegiatan Rekonstruksi Sarana dan Prasarana Pasar Tugu Kota Depok”. Jurnal Rona Teknik Pertanian, Vol.13, No.1, April 2020.

BPS Kota Depok. (2019). Kecamatan Cimanggis dalam Angka Tahun 2019. Badan Pusat Statistik. Kota Depok. 
Ervianto, I.W. (2005). Manajemen Proyek Konstruksi. Edisi Revisi. Penerbit Andi. Yogyakarta. KepMen LH 48/96. Keputusan Menteri Negara Lingkungan Hidup Nomor 48 Tahun 1996 tentang Baku Tingkat Kebisingan.

KepMen LH 50/96. Keputusan Menteri Negara Lingkungan Hidup Nomor 50 Tahun 1996 Tentang Baku Tingkat Kebauan.

PerMenKes 32/17. Peraturan Menteri Kesehatan Republik Indonesia Nomor 32 Tahun 2017 tentang Standar Baku Mutu Kesehatan Lingkungan Dan Persyaratan Kesehatan Air Untuk Keperluan Higiene Sanitasi, Kolam Renang, Solus Per Aqua, Dan Pemandian Umum.

PP 27/12. Peraturan Pemerintah Republik Indonesia Nomor 27 Tahun 2012 tentang Izin Lingkungan.

PP 41/99. Peraturan Pemerintah Republik Indonesia Nomor 41 Tahun 1999 Tentang Pengendalian Pencemaran Udara.

Rellua, Olivianty (2013). "Proses Perizinan dan Dampak Lingkungan Terhadap Kegiatan Reklamasi Pantai”. Jurnal Elektronik Bagian Hukum Administrasi dan Negara Fakultas Hukum Universitas Sam Ratulangi. Vol.1, No.2. P 158-167.

Razif, Mohammad (2018). "Peranan Aspek Lingkungan dalam Manajemen Aset Infrastruktur dan Fasilitas". Jurnal Manajemen Aset Infrastruktur \& Fasilitas, 2(2), September 2018.

Salim, Emil (1976). Masalah Pembangunan Ekonomi Indonesia. Lembaga Penerbit Fakultas Ekonomi Universitas Diponegoro. Semarang

Soedjono (1979). Pengaman Hukum Terhadap Pencemaran Lingkungan Akibat Industri. Penerbit Alumni. Bandung.

Soemarwoto, Otto (1983). Ekologi, Lingkungan Hidup dan Pembangunan. Djambatan. Jakarta.

Suprayitno, H. \& Soemitro, R.A.A. (2018). "Preliminary Reflexion on Basic Principle of Infrastructure Asset Management”. Jurnal Manajemen Aset Infrastruktur \& Fasilitas, Vol. 2, No. 1, Maret 2018.

UU 32/09. Undang-Undang Republik Indonesia Nomor 32 Tahun 2009 tentang Perlindungan dan Pengelolaan Lingkungan Hidup. 